\title{
No fue suerte, estaba preparado: la filosofía de la suerte de Axel Barceló
}

\section{[It Was Not Luck, I Was Prepared: Axel Barceló's Theory of Luck]}

\author{
JULEN IBARRONDO MURGUIALDAY \\ Universidad Autónoma de Madrid \\ julibamur@gmail.com
}

\begin{abstract}
Resumen: En este trabajo expongo la concepción de la suerte que defiende Axel Barceló en su libro Falibilidad y normatividad. Un análisis filosófico de la suerte. De acuerdo con Barceló, la suerte es un concepto irreductiblemente normativo mediante el cual el agente obtiene un resultado con un procedimiento para el que no estaba preparado. Este nuevo enfoque arroja luz sobre problemas filosóficos aparentemente muy distintos, como el papel de la suerte en nuestras evaluaciones epistémicas y morales, el problema de la vaguedad o los modales epistémicos. Defiendo que, si bien la propuesta adolece de ciertos problemas a la hora de vincular el hecho de estar preparado con actuar con responsabilidad, el espíritu general de la teoría de Barceló presenta ventajas notables respecto a las teorías alternativas.
\end{abstract}

Palabras clave: falibilidad; normatividad; responsabilidad; vaguedad; modales epistémicos

\begin{abstract}
In this work I introduce Barceló's account of luck as put forward in his book Fallibility and Normativity. A Philosophical Analysis of Luck. According to Barceló, luck is an irreducibly normative notion that points to the fact that an agent has achieved an aim in a way he was not prepared for. This new view brings light to apparently very diverse philosophical problems, such as the role of luck in our epistemic and moral evaluations, the vagueness problem, or epistemic modals. I argue that, even though this proposal must deal with some problems when tracing the link between being prepared and acting responsibly, the overall spirit of Barcelós theory enjoys significant advantages over alternative theories of luck.

Key words: fallibility; normativity; responsibility; vagueness; epistemic modals
\end{abstract}

\section{Introducción}

En su reciente libro Falibilidad y normatividad. Un análisis filosófico de la suerte (2019), Axel Arturo Barceló Aspeitia analiza de una manera unificada y transversal poco común en los debates filosóficos actuales la naturaleza de la suerte y su papel en nuestras prácticas evaluativas. La obra presenta además una caracterización de la suerte como la ausencia de preparación que nos provee de una manera nueva y prometedora de enmarcar todos estos problemas. 
En la primera sección expongo la noción de "practica falible" tal como la usa Barceló y muestro cómo nos permite abordar de manera similar problemas aparentemente tan dispares como los casos Gettier, la suerte moral, la vaguedad o la semántica de los modales epistémicos. En la segunda sección desarrollo la concepción de la suerte como ausencia de preparación y la comparo con otras concepciones de la suerte, tales como la suerte como lo improbable o como ausencia de control. Por último, en la tercera sección, presento algunos problemas posibles en la manera en la que la teoría de Barceló relaciona el hecho de estar preparado con actuar responsablemente.

\section{Prácticas falibles}

En retrospectiva, podemos afirmar que uno de los cambios más significativos de la filosofía en los últimos cincuenta años es la consideración de la suerte como un problema fundamental. Es verdad que hay excepciones notables; ciertamente existen estudios filosóficos sobre la suerte desde la Antigüedad, y muy en especial en el ámbito de la ética. No obstante, el papel de esta noción se reducía entonces de manera casi inexorable a ser una fuerza externa que, en el mejor de los casos, podía inclinarse a nuestro favor mediante la casuística (como en los oráculos de prudencia y en los manuales para gobernantes) y, en los peores, debía simplemente sobrellevarse (como en el género de las consolaciones). Aun si se reconocía como una dimensión crucial de la fragilidad humana, en la práctica ocupaba un lugar marginal en la teorización filosófica más canónica, donde primaban los ideales de la certeza en la teoría del conocimiento y de la pureza en la motivación moral, las cuales se concebían como inmunes a la suerte.

Sin embargo, la tendencia actual es en gran medida muy distinta. Muchos de los debates más importantes en la filosofía contemporánea involucran discusiones acerca del papel de la suerte en el seno de nuestras prácticas epistémicas, morales, políticas y científico-tecnológicas. De acuerdo con este nuevo enfoque, la suerte no constituye tanto un peligro a desterrar en estas áreas, sino un elemento más (y uno especialmente importante) al que tenemos que buscarle un lugar propio. No se trata ya de desarrollar teorías que garanticen la inmunidad frente a la suerte, sino de que recojan y articulen las maneras en las que nuestras distintas prácticas son sensibles a ella.

Esta nueva concepción ha resultado ser muy prolífica, en especial en la ética y la epistemología. Gracias a Williams 1981 la suerte moral, el hecho de que la condición moral de nuestras acciones pueda depender 
de nuestra buena o mala suerte, es ahora un apartado importante de la filosofía moral actual e ilumina aspectos que la fijación tradicional por construir teorías morales inmunes a la suerte no había abordado. Por otro lado, una gran parte de la epistemología ha renunciado después de la obra de Gettier a seguir con la obsesión tradicional por asentar la certeza del conocimiento frente a los envites escépticos para, en su lugar, estudiar las maneras en las que los sujetos obtienen conocimiento en entornos que no son inmunes a la suerte.

De acuerdo con esta nueva forma de ver el éxito moral y epistémico, podemos llegar a saber algo o a comportarnos de manera adecuada mediante procedimientos que no son inmunes a la suerte. Por ejemplo, parece obvio que alguien puede saber cuándo es su cumpleaños gracias a sus propios recuerdos acerca de la fecha en que lo celebró en años anteriores o del testimonio de sus padres o de otras personas que sepan cuándo nació. Que alguien crea en verdad que cierto día es su cumpleaños a partir de dichas fuentes suele ser suficiente para que de hecho sepa cuándo es su cumpleaños. Ahora bien, ninguno de esos cauces para saber cuándo es nuestro cumpleaños es inmune a la suerte. Alguien podría ser engañado por los otros o equivocarse al intentar recordar cuándo es su cumpleaños. De ser así, no sabríamos cuándo es nuestro cumpleaños. La famosa aportación de Gettier consiste en recalcar que seguir los procedimientos que normalmente serían eficaces y alcanzar el fin no bastan para descartar que se haya obtenido una creencia verdadera por suerte.

Sin embargo, hay un aspecto aún más importante para el tema en cuestión. El hecho de que la mala suerte pueda evitar que alguien sepa cuándo es su cumpleaños cuando apela a la memoria o al testimonio es compatible con que, cuando todo marcha según lo previsto sin injerencias de la suerte, la memoria y el testimonio sean suficientes para elevar la creencia verdadera al rango de conocimiento. Las condiciones que hacen que conozcamos en los casos normales en los que no somos víctimas de la suerte no tienen por qué ser tan férreas como para garantizar que también conoceríamos si nos encontráramos en un escenario de mala suerte. Mis recuerdos o el testimonio de terceros son fuentes legítimas de conocimiento aun si no pueden garantizarnos que no haya casos de mala suerte en los que estas fuentes no nos otorguen conocimiento.

Lo mismo sucede en el ámbito práctico. Imaginemos que un padre decide inscribir a su hijo en un colegio que, según todo lo que ha investigado, es el idóneo para el niño. Normalmente eso sería suficiente para aceptar que el padre ha actuado de la forma correcta. Ahora bien, 
imaginemos que, contra todo pronóstico, el niño acaba en una clase en la que los demás compañeros lo maltratan sin que su tutor, uno de los pocos maestros incompetentes en la escuela, haga nada al respecto. Si todo hubiera marchado según lo previsto y el niño no hubiera acabado en manos de los abusones y de uno de los pocos maestros incompetentes, sin duda habríamos dicho que el padre hizo lo correcto al mandar a su hijo a ese colegio. No obstante, en el caso de mala suerte en el que el niño acaba en una clase así, el padre hizo mal en elegir ese colegio para su hijo. Aun así, el padre no necesita elegir el colegio de su hijo con base en criterios que hagan de su elección algo inmune a la mala suerte para que, si no hay mala suerte, la elección del colegio constituya una buena elección por su parte y no una elección afortunada.

A partir de las semejanzas entre los casos epistémicos y morales podemos definir ciertas prácticas como falibles de la siguiente manera:

Práctica falible: una práctica es falible si, al tener como objeto alcanzar un fin $f$, hay un procedimiento $m$ tal que basta con que un agente obtenga $f$ mediante $m$ para que consideremos que alcanzó $f$ de manera merecida y, sin embargo, es posible llevar a cabo $m$ y no obtener $f$.

Las prácticas falibles son vulnerables a la suerte: aunque exista un procedimiento que permita que el sujeto alcance su objetivo de manera meritoria, el procedimiento no garantiza que se obtenga el fin previsto. Así, aunque apelar a la memoria y al testimonio es suficiente para que, si se dan las circunstancias apropiadas, alguien sepa cuándo es su cumpleaños, de manera tal que mantener esa creencia verdadera es un logro atribuible al agente, la apelación a la memoria y al testimonio no garantizan la verdad de la creencia. Si no se consigue el fin a pesar de haber seguido el procedimiento, entonces estamos ante un caso de mala suerte.

Es importante resaltar que esta concepción del papel de la suerte en muchas de nuestras prácticas conlleva una asimetría interesante. Si bien somos víctimas de la mala suerte cuando llevamos a cabo el procedimiento pertinente pero no obtenemos el fin, en los casos en los que obtenemos el fin gracias al procedimiento adecuado no gozamos de buena suerte; en estos casos decimos que el agente ha logrado el objetivo de manera meritoria. Si me formo una creencia verdadera acerca de la fecha de mi cumpleaños a partir de memorias y testimonios fidedignos, el hecho de que mi creencia sea verdadera no es un caso de buena suerte: sé cuándo es mi cumpleaños y esto constituye un logro epistémico que ha de atribuírseme. 
Los casos de buena suerte son aquellos en los que se obtiene el fin en cuestión sin seguir los procedimientos pertinentes. No es cuestión de buena suerte que alguien obtenga dinero a fin de mes por su trabajo, pero sí lo es el que se encuentre un tesoro a raíz de hacer obras en su casa. El padre de nuestro ejemplo tendrá suerte en la elección del colegio si, tras no haber hecho las indagaciones pertinentes, resulta ser excelente para su hijo. Pero, si elegir ese colegio es el resultado de un cuidadoso proceso de selección, entonces parece más apropiado decir que el padre ha logrado elegir un buen colegio para su hijo y no que ha tenido buena suerte.

Si bien estas consideraciones son ya bien conocidas en el campo de la ética y la epistemología, es mérito de Barceló percatarse de que este modelo abarca todas las actividades en las que las condiciones por las que un éxito constituye un logro no garantizan la obtención de éste (Barceló 2019, pp. 36-39). Me limitaré a comentar de manera breve dos casos especialmente interesantes de entre los que señala Barceló: la semántica de los modales epistémicos y el problema de la vaguedad.

A menudo nos retractamos de afirmaciones que incluyen modales epistémicos tales como "es posible que Jaime no venga a visitarnos este verano" o "Alba no está en el trabajo así que tiene que estar en casa". La paradoja estriba en que, dado que el hablante afirma cuán comprometido está con una proposición a la luz de la información de la que dispone en dicho momento, un cambio en la evidencia disponible supondría nuevas condiciones de evaluación. Aunque el hablante puede modificar su nivel de compromiso doxástico respecto a una proposición (por ejemplo, ahora está seguro de que Jaime no vendrá y de que Alba puede no estar en casa) no está claro por qué eso debería constituir una retractación de su afirmación anterior. A fin de cuentas, en virtud de la información disponible, era posible que Jaime no viniera y que Alba tenía que estar en el trabajo. No es obvio cómo añadir más información después afecta a lo que entonces era o no posible en relación con la perspectiva epistémica del agente en aquel momento.

Barceló cree que deberíamos considerar que este tipo de casos involucra una dosis importante de falibilidad. Cuando decimos que Alba tiene que estar en el trabajo afirmamos que, a raíz de la información de la que disponemos, no contemplamos ningún escenario en el que Alba resulte estar en otro lugar. Esta afirmación puede resultar competente, puede ser una forma adecuada de responder a la evidencia de la que dispone el hablante, y aun así ser falsa en virtud de la mala suerte (por ejemplo, puede pasar algo completamente inesperado que provoque que, contra todo pronóstico, Alba no esté en el trabajo). Esta 
perspectiva nos ayuda a desentrañar por qué, si bien queremos decir que en cierto sentido el hablante pudo actuar de manera apropiada al afirmar que Alba tenía que estar en el trabajo, una vez que descubre que se equivocó esperamos que se retracte de esa misma afirmación. A pesar de que fue competente al afirmar que Alba tenía que estar en cierto sitio, la mala suerte hizo que afirmara algo falso (Barceló 2019, p. 113).

Este enfoque también resulta interesante cuando lo aplicamos a las cuestiones metafísicas tradicionales sobre la vaguedad. Barceló defiende que deberíamos concebir nuestros conceptos como herramientas falibles (Barceló 2018, pp. 147-157). En el caso de los conceptos vagos, si bien pueden aplicarse normalmente sin problemas, hay casos límite en los que su uso se vuelve incierto. Barceló argumenta que debemos considerar su incapacidad para clasificar en estas circunstancias como casos de mala suerte, situaciones para las que nuestros conceptos no están preparados. Lo importante aquí es que, dada la asimetría a la que me refería antes, el hecho de que en los casos de mala suerte alguien haya usado los medios apropiados pero no obtenga el fin no implica que cuando obtiene el fin gracias a los medios pertinentes goce de buena suerte. Así, el hecho de que en ciertos contextos límite nuestros conceptos no puedan usarse de forma apropiada no implica que no podamos usar esos mismos conceptos en los casos no problemáticos: que no sepa cuándo alguien pasa a ser calvo no significa que no haya muchas situaciones en las que pueda discernir los calvos de los que no lo son. En estos casos, tener éxito en nuestro afán clasificador no es una cuestión de buena suerte. ${ }^{1}$

Se ve así que, para Barceló, la falibilidad es una característica fundamental no sólo de la agencia humana tal y como se entiende tradicionalmente en la epistemología y en la ética, sino que también se aplica a todo sistema, herramienta o mecanismo que podamos describir como capaz de orientarse hacia un fin de manera exitosa mediante procedimientos que no garantizan la obtención de éste. Basta con que podamos considerar que el objeto en cuestión tiene formas meritorias de alcanzar un fin para que podamos evaluar el papel que la suerte desempeña en cada una de sus actuaciones. Así, nada impide que, de entrada, adjudiquemos buena o mala suerte a mecanismos tecnológicos o instituciones sociales en la consecución de los fines que les son propios.

\footnotetext{
${ }^{1}$ Resulta interesante preguntarse si hay casos en los que un concepto vago pueda aplicarse de manera exitosa por un caso de buena suerte. Hasta donde sé, Barceló no aborda esta cuestión, pero sería de esperar que, a fin de mantener la analogía con la ética y la epistemología, estos casos también fueran posibles.
} 


\section{La suerte como ausencia de preparación}

El eje central de la propuesta de Barceló consiste en afirmar que podemos dar cuenta de cómo la suerte afecta a la dimensión normativa de las prácticas falibles a partir de una concepción general de la suerte que puede aplicarse por igual a las acciones de agentes individuales y colectivos. Para ello, y aquí estriba la originalidad de la propuesta, lo que necesitamos es una concepción normativa de la suerte. Según Barceló, el papel fundamental de las atribuciones de buena y mala suerte no es el de evaluar acontecimientos como más o menos probables, sino que dichos acontecimientos se den fuera de los cauces mediante los cuales esperaríamos que el agente consiga de forma meritoria el objetivo de la tarea que realiza.

A lo largo del libro Barceló insiste en que lo crucial para nuestras evaluaciones acerca de si alguien logró sus fines de forma meritoria, si fracasó por su culpa o si el resultado fue una cuestión de suerte, no es qué tan probable era obtener el objetivo dadas las circunstancias; la suerte no es el éxito o el fracaso improbables. Que David venciera a Goliat era cosa muy improbable, pero no diríamos que fue pura suerte, como sí lo diríamos si a Goliat le hubiera caído una maceta en la cabeza, al margen de qué tan probable fuera que David derrotara a Goliat con su honda o que la maceta cayera sobre Goliat. Según Barceló, estas intuiciones se explican a partir del hecho de que nuestras evaluaciones acerca de la suerte entrañan una dimensión normativa: “[L]a noción misma de 'suerte' no es meramente descriptiva, sino también normativa. Haber tenido suerte es haber obtenido algo que no se ha ganado" (Barceló 2019, p. 53). Que la piedra lanzada por David derribara a Goliat es algo que David "se ganó" de una forma en la que no lo hubiera hecho con la caída de la maceta, no porque fuera más improbable que cayera una maceta en ese momento (podemos admitir que el que la piedra lanzada por David dañara a Goliat era también muy improbable), sino porque los medios que empleó David, lanzar una piedra con su honda de forma certera, lo hacen merecedor de su victoria sobre Goliat.

Hay ciertas vías que los agentes pueden tomar y con las que diríamos que éstos alcanzaron su objetivo en forma merecida y no porque tuvieron buena suerte. Ahora bien, en las prácticas falibles estas vías no garantizan la consecución del objetivo; en ellas no somos inmunes a la mala suerte. De igual manera, hay casos en los que no se toma ninguna de las vías que consideraríamos que harían merecedor al agente de alcanzar su propósito y, a pesar de ello, tiene éxito. Éstos son los 
casos de buena suerte. Barceló llama "estar preparado" a seguir un procedimiento de este tipo. Si seguimos con nuestro ejemplo, en el relato bíblico David estaba preparado para abatir a Goliat con su honda: tenía su honda en la mano, había ejercitado con ella previamente, apuntó de forma serena al blanco, etc. Esto explica por qué no consideramos la victoria de David como un mero caso de buena suerte. Sin embargo, que una maceta golpee a Goliat no es una forma de derrotar a Goliat para la que David se hubiera preparado (por supuesto, la cosa sería bien distinta si la maceta fuera parte de una estratagema orquestada por David). Dado el fin de una actividad, es posible prepararse de distintas maneras para alcanzarlo. Si el objetivo surge de una forma desvinculada de la manera en que uno se preparó, entonces se ha obtenido gracias a la buena suerte.

Barceló argumenta que esto es justo lo que ocurre en los casos Gettier: el hombre que cree que quien obtendrá el puesto tiene varias monedas en el bolsillo está preparado para sostener esa afirmación sobre la base de que la persona que tiene buenos contactos en la empresa tiene varias monedas en el bolsillo. Es por ello que su creencia será verdadera gracias a la buena suerte si resulta ser él quien recibe el puesto $\mathrm{y}$ tiene varias monedas en el bolsillo. Al igual que con Goliat y la maceta, aunque se alcanza un objetivo (en este caso, creer algo verdadero) para el que uno estaba preparado, los acontecimientos transcurrieron por una senda que no era para la que uno se había preparado y, por lo tanto, si bien el agente ha podido obrar de manera responsable y competente, el logro no es propiamente suyo, sino fruto de la buena suerte.

Ahora bien, se podría pensar que, si merecer el logro sólo es posible en virtud de estar preparado, alguien debería estar "absolutamente preparado" a fin de que su logro no sea fruto de la suerte. Si dejamos muchas posibilidades abiertas, entonces que las cosas acontezcan de acuerdo con nuestros planes dependerá del azar, con lo que obtener el objetivo se deberá a la buena suerte. Es fácil ver cómo esta línea de razonamiento podría llevarnos de nuevo a equiparar la suerte con la probabilidad. Barceló evita este problema al defender que no se necesita estar absolutamente preparado a fin de merecer el objetivo:

En sentido estricto, lo que distingue a quien está preparado (en el sentido que aquí me interesa) no es la pura cantidad de situaciones para las que está preparado, sino el tipo de situaciones para las que está preparado. Prepararse para un posible huracán cuando se vive en zona de huracanes es racional y responsable en un sentido que no lo es prepararse para una 
invasión extraterrestre. Por eso, a la persona que se preparó para una invasión extraterrestre que no sucedió, pero no para un huracán previsible no le decimos que tuvo mala suerte, sino que fue negligente; mientras que a la persona que no se preparó para una invasión extraterrestre imprevisible no la juzgamos negligente, sino a lo más, de tener mala suerte. (Barceló 2019, p. 55)

Lo que ilustra este ejemplo es que alguien no necesita actuar de manera que el fin se dé en todos los mundos posibles futuros para que el resultado no sea fruto de la suerte. Esto es importante por dos motivos: en primer lugar, es precisamente porque no nos podemos preparar para todos los acontecimientos futuros posibles que estas prácticas son falibles. Si pudiéramos prepararnos para todos los escenarios posibles entonces nuestra preparación garantizaría el éxito y no habría casos de mala suerte, sino sólo errores culpables que han de atribuirse a nuestra falta de preparación. En segundo lugar, esto explica por qué la noción de suerte es irreductiblemente normativa. Puesto que no podemos prepararnos para todas las situaciones posibles, necesitamos priorizar nuestros recursos y discernir entre las situaciones para las que tenemos que prepararnos y las que no.

En esto último es importante recordar además que las situaciones para las que uno debe prepararse no son necesariamente las más probables. Desde luego, uno debería asegurar su casa contra incendios, pero no contra que alguien manche el antiguo sofá del salón, si bien lo segundo es mucho más probable que lo primero. La explicación es obvia: aunque mucho más improbable, la gravedad de lo que está en juego hace que tomemos medidas contra lo primero, pero no contra lo segundo. De igual forma, hay casos en los que sencillamente los costes de prepararse para algo, aunque sea muy probable, son tan elevados que no es razonable exigir que nos preparemos contra ello (piénsese en cuánto estamos realmente dispuestos a hacer para prevenir nuestra muerte en algún punto indefinido del futuro). ${ }^{2}$ En definitiva, no hay una forma libre de valores para determinar cuánto y en qué sentido deberíamos prepararnos, dado que prepararse involucra seleccionar los escenarios relevantes. Cuáles sean relevantes no se determina en forma exclusiva por lo probables que sean, sino también por el balance de

${ }^{2}$ Barceló no es del todo claro en este detalle, pero parece defender que, en última instancia, el hecho de que debamos o no prepararnos para algo es una función de los costes o beneficios asociados a alcanzar el objetivo, el coste de oportunidad de prepararnos y lo probable que es alcanzar el objetivo si nos preparamos de dicha forma. Véase, por ejemplo, p. 130. 
costes y beneficios asociados a la preparación. En definitiva, el concepto de suerte es intrínsecamente normativo porque se encuentra ligado de manera íntima con una evaluación acerca de para qué situaciones es razonable (y exigible) prepararse.

Esta dimensión normativa irreductible es lo que distingue la concepción de la suerte de Barceló de otras recientes que vinculan la suerte con la ausencia de control. ${ }^{3}$ Ambos enfoques comparten la idea de que algo puede ser fruto de la suerte con independencia de cuán probable sea porque podemos no tener control sobre acontecimientos que son muy probables. Sin embargo, la concepción de Barceló resulta más liberal que las teorías que ligan la suerte con el control. Aunque Barceló parece estar de acuerdo en que no podemos estar preparados si adoptamos ciertos medios a menos que la adopción de dichos medios esté bajo nuestro control, sostiene que hay situaciones en las que, si bien está bajo nuestro control tomar ciertos medios para prepararnos a fin de alcanzar nuestro objetivo, podemos aun así no adoptar dichos medios y que el consecuente resultado desafortunado sea un caso de mala suerte. De nuevo, para Barceló no todos los medios que están en nuestra mano son exigibles: bien puede estar bajo nuestro control tomar ciertas medidas contra una posible invasión extraterrestre pero, puesto que no es razonable prepararse para ese escenario, que la invasión alienígena nos encuentre indefensos no es un error de nuestra parte, sino un caso de mala suerte.

A mi juicio, esta dimensión normativa constituye una de las principales ventajas de la concepción de Barceló sobre las teorías alternativas porque casa fácilmente con un enfoque muy atractivo acerca del papel que desempeña la atribución de suerte en nuestras prácticas evaluativas y que no pueden abordar tan fácilmente las teorías alternativas como las que vinculan la suerte con la probabilidad o con la ausencia de control. ¿Por qué nos importa si los agentes, mecanismos, instituciones o grupos obtienen los fines propios de ciertas actividades por buena suerte o por mérito propio? ¿Por qué debería importarnos si el fracaso es atribuible a la mala suerte o al agente? Es evidente que la pregunta de si alcanzar un objetivo fue un logro atribuible a un agente es muy distinta de cuán probable era que lo alcanzara (sacar un cinco o menos en un dado es muy probable, pero no es un logro que pueda atribuírsele al jugador). De igual manera, si nuestro concepto de suerte significara una mera ausencia de control, a fin de no cometer un fallo del que somos responsables deberíamos tomar todos los medios bajo nuestro

${ }^{3}$ Véase, por ejemplo, Broncano-Berrocal 2015.

Diánoia, vol. 66, no. 86 (mayo-octubre de 2021) • elSSN 1870-4913

DOI: 10.22201/iifs.18704913e.2021.86.1830 
control suficientes para garantizar que no cometemos un error del que somos responsables. Pero, en muchos casos, los medios y el fin son de tal naturaleza que lo que nos importa no es si el agente hizo todo lo que estaba bajo su control, sino si hizo todo cuanto era razonable dada la situación.

En cambio, la teoría de Barceló engarza bien con una imagen razonable de qué es lo que nos interesa en este tipo evaluaciones. De acuerdo con el autor, para cada actividad en la que un agente se propone lograr un fin hay al menos dos preguntas que podemos hacernos: ¿alcanzó el agente el fin? Y ¿estaba el agente bien orientado hacia la obtención del fin? En las actividades falibles la respuesta para cada una de estas preguntas es independiente de la otra.

El último capítulo del libro se dedica a argumentar que las diferencias entre estos dos tipos de evaluaciones deben concebirse en términos de dos propiedades distintas. Al contrario de lo que defenderían ciertos tipos de consecuencialismo o de deontologismo, ninguna de las dos es más fundamental que la otra en ningún sentido interesante. El consecuencialista está en lo cierto en que el fin de nuestras acciones rara vez es manifestar una conducta responsable, sino obtener ciertos fines externos y que, por lo tanto, la pregunta de si hemos obtenido o no nuestros fines cuando evaluamos la conducta es pertinente. No obstante, el deontologista tiene razón en resaltar la importancia de la actitud del agente al intentar obtener el fin en cuestión y de si actuaba o no de manera responsable. No hay ningún motivo para pensar que obtener el fin sea lo único importante de nuestras acciones ni que lo sea conducirse responsablemente.

Esta dualidad no debería concebirse como una forma de relativismo al estilo de MacFarlane 2014 según la cual evaluamos un mismo objeto (si el agente hizo lo correcto) desde dos perspectivas diferentes, tal y como lo haríamos con "los caracoles son deliciosos" que es verdadero relativo a ciertos agentes, a quienes les gustan, pero no para otros. Los argumentos de Barceló son convincentes: cuando una persona afirma que el conductor hizo algo horrible al atropellar (accidentalmente) a alguien y otro que fue mala suerte porque ocurrió a pesar de que conducía con cuidado, lo que tenemos no son dos personas haciendo la misma evaluación desde perspectivas diferentes (como sostendría el relativista), sino dos personas que evalúan dos aspectos distintos. El primero afirma que atropellar a alguien fue un mal resultado, mientras que el segundo insiste en que el conductor conducía de manera responsable y que el atropello fue fruto de la mala suerte (Barceló 2019, pp. 113-114). 
Dado que conducir de forma segura es una práctica falible, la prudencia del conductor no garantiza que no haya un desenlace trágico en el que termine atropellando a alguien. Esto explica también en qué sentido el conductor hizo algo genuinamente malo al atropellar a alguien inocente (ésta es la baza del consecuencialista), y no meramente malo desde cierto punto de vista, como defiende el relativista. Aunque exoneramos al conductor de culpa en la medida en la que estaba razonablemente preparado para evitar atropellar a alguien (y éste es el punto fuerte del deontologista) también es cierto que, posiblemente, podía haber estado más preparado de tal manera que habría podido evitar el accidente. Esto explica por qué esperamos que el conductor se sienta culpable por lo que hizo a la par que los demás intentamos consolarlo diciéndole que no fue culpa suya (Barceló 2019, p. 114).

Además del asunto de si alcanzó el fin y de si estaba razonablemente preparado para alcanzarlo, podemos preguntarnos si el agente tuvo éxito porque estaba preparado. Aquí es donde debemos lidiar con casos tipo Gettier, en los que se obtiene el fin gracias a la buena suerte a pesar de una falta de preparación. Para Barceló, alguien alcanza el fin porque estaba preparado si la situación forma parte de un espacio de mundos posibles en el que el agente puede garantizar que se obtendrá el objetivo (Barceló 2019, p. 54). Así, por ejemplo, yo estoy preparado para aprobar el examen si sale el tema 1 si, y sólo si, en todos los mundos posibles en los que sale el tema 1 resulta que apruebo el examen. Si en el examen sale el tema 1 y apruebo, entonces mi éxito no es atribuible a la suerte. Ahora bien, imaginemos que estudio un número suficiente de temas, de manera que estoy bien preparado para el examen, pero que no he estudiado el tema 87, por lo que no estoy en situación de garantizar que apruebe si me preguntan por el tema 87. Si sale el tema $87 \mathrm{y}$ aun así apruebo (por ejemplo, aunque no contaba con ello, alguien más en el examen me dice la respuesta) entonces, a pesar de estar preparado para aprobar, he aprobado por buena suerte.

\section{Algunos problemas para la teoría de Barceló: preparación y responsabilidad}

Si bien la propuesta de Barceló ofrece ventajas significativas respecto a otras caracterizaciones de la suerte, entender la suerte como estar preparado no está exento de ciertos problemas. En este último apartado quisiera centrarme en señalar que a menudo cuál sea la forma razonable de prepararse para un acontecimiento depende de nuestra perspectiva epistémica, lo cual puede no ser suficiente para que estemos 
genuinamente preparados. Esto dificulta mucho que podamos vincular la noción de actuar responsablemente con el hecho de estar preparado de una forma tan estrecha como pretende Barceló.

Imaginemos el caso en el que alguien se prepara para un fin $f \mathrm{y}$ adopta los medios $m$ porque, dada la información con la que cuenta, es razonable hacer $m$ para obtener $f$. Ahora bien, resulta que $m$ no es en realidad una forma de prepararse para $f$ : no es el caso que en los mundos posibles en los que realizamos $m$ obtenemos $f$. Podemos pensar que el agente tiene una creencia razonable pero falsa acerca de que $m$ es una buena forma de prepararse para obtener $f$. Por lo tanto, éste es un caso en el que el agente estaba preparado para creer que $m$ era una buena forma de prepararse para $f$ pero tuvo mala suerte y su creencia resultó ser falsa. ¿Cómo afecta el hecho de que su creencia sea falsa, aunque se haya preparado en forma adecuada para sostenerla, al estatus de su conducta respecto a la obtención de $f$ ?

$\mathrm{Al}$ actuar con base en esa creencia, el agente no es irresponsable, pues está preparado para sostenerla. Sin embargo, dado que los medios que va a emplear no son realmente efectivos, no pueden garantizar la obtención de $f$ en el conjunto de mundos posibles para el que es razonable prepararse. Así, parece que, si bien el agente está preparado para sostener la creencia de que $m$ es un buen medio para $f$, realizar $m$ no lo preparará para obtener $f$.

Supongamos ahora que, en virtud de una cadena causal enrevesada que no contempló el agente, éste obtiene $f$ gracias a que hizo $m$. ¿Cómo evaluar un caso así? Por un lado, parece que tuvo suerte, pues realmente $m$ no es una buena manera de prepararse para $f$. Pero, por otro lado, en cierto sentido las cosas ocurrieron como el agente había previsto porque, tal y como era razonable creer dada su posición epistémica, adoptar $m$ lo llevó a obtener $f$. Parece entonces que lo que finalmente aconteció era algo para lo que estaba preparado. No obstante, según la definición de Barceló de en qué consiste estar preparado, en realidad no lo estaba.

El problema estriba en que la caracterización que ofrece Barceló de que una situación sea previsible está más constreñida por la perspectiva epistémica del agente que la noción de estar preparado. El autor entiende lo previsible como aquello que uno de manera responsable ha de tomar en consideración. Tal es el sentido en el que las invasiones alienígenas son imprevisibles y no meramente improbables (Barceló 2019, pp. 52-53). Ahora bien, parece que si los alienígenas ya han decidido invadirnos, no por ello la invasión es más previsible para quienes no estamos en situación de saber lo que traman; aunque la invasión 
es muy probable, sigue siendo muy imprevisible para nosotros. Parece razonable suponer entonces que cuán previsible sea una situación para un agente depende de su perspectiva epistémica. Sin embargo, el estar preparado no depende de si desde nuestra perspectiva epistémica nos parece que podemos prever que en los mundos posibles relevantes en los que hacemos $m$ también obtenemos $f$, sino de si realmente en los mundos posibles relevantes en los que hacemos $m$ (y no sólo los que nosotros juzgamos relevantes) obtenemos $f$.

No es obvio cómo podría evitarse el problema. Si optamos por suponer que el estar preparado no depende de que creamos responsablemente en la eficacia de $m$ para $f$, sino que basta con que adoptemos $m$ y que $m$ sea una buena forma de prepararnos para $f$, entonces podemos estar preparados sin actuar de forma responsable. Esta salida es manifiestamente errónea, dado que implica que se pueden obtener logros de manera irresponsable, lo cual desdibuja la distinción entre tener buena suerte y lograr el objetivo de forma merecida.

Por otro lado, si para estar preparado basta con prepararnos con creencias que sostenemos de manera responsable, entonces podemos tener éxito en unas circunstancias para las que estábamos preparados, pero por suerte; puesto que, en nuestro ejemplo, es un caso de buena suerte el que el medio por el que se optó (responsablemente) resultara ser una buena forma de prepararse. El agente estaba preparado para obtener $f$ mediante $m$ y obtuvo $f$ mediante $m$ pero sólo porque tuvo buena suerte. Pero, si esto es así, entonces tenemos que abandonar una de las tesis principales de la teoría de Barceló: alcanzar el objetivo por buena suerte no es lo mismo que alcanzarlo de una manera para la que no se estaba preparado, por lo que no es cierto que la suerte consista en obtener un resultado de una manera para la que no se está preparado.

Hay una tercera opción más verosímil. Podemos insistir en que para estar preparado y que el éxito no sea fruto de la suerte, debemos saber que los medios por los que optamos son los adecuados; sólo entonces podremos decir que un agente estaba genuinamente preparado para obtener $f$ mediante $m$. Esta idea tiene cierto atractivo. Podemos concebir la actividad de prepararse para $f$ en dos pasos: Primero, debemos lograr saber si $m$ es una buena estrategia para obtener $f$. Si tenemos un éxito merecido en esta empresa, podemos pasar a considerar si hemos obtenido $f$ en virtud de aplicar el conocimiento adquirido. Sólo se puede obtener un éxito merecido si a su vez se ha logrado un éxito merecido en cada uno de estos dos estadios. Los casos en los que obtenemos $f$ sin satisfacer ambas condiciones son casos de buena suerte. 
Ésta parece ser la mejor salida para la teoría de la suerte como ausencia de preparación. Sin embargo, el resultado no deja de ser un tanto decepcionante. A fin de cuentas, uno de los principales atractivos de la teoría era distinguir entre las evaluaciones en las que nos preguntamos si se obtuvo el fin previsto y el asunto de si el agente estaba bien preparado para obtenerlo. Ahora nos vemos obligados a trasladar esta contraposición inicial de la acción al prepararse, de tal manera que para saber si alguien estaba preparado con $m$ para obtener $f$ debemos preguntarnos primero si estaba preparado para lograr prepararse. El problema aquí no es tanto el de una regresión ad infinitum, como que las evaluaciones acerca de si alguien estaba o no preparado no podrán ya equipararse con el detalle de si el agente actuó responsablemente, dado que en el prepararse ya está incluido el no haber sido víctima de la suerte.

Podemos preguntarnos si esto es un problema sólo para agentes como los seres humanos o si también se reproduce en los casos en los que tratamos con artefactos, instituciones sociales, etc. No sé hasta qué punto hay aquí algo análogo a comportarse responsablemente que pueda aplicarse a los artefactos o a las instituciones. Quizá es posible caracterizarlos en términos teleológicos de funcionamiento normal, de tal forma que estos "agentes" actuarían "responsablemente" si hacen aquello que en condiciones normales conllevaría que satisficieran su función. ${ }^{4}$ Obviamente, la cuestión es más sencilla si pensamos en tipos de agencia para tareas que involucran actuar con base en cierta información que puede ser errónea. Si tiene sentido describir un comportamiento en estos términos, entonces también habrá casos en los que actuar de manera responsable no será suficiente para estar preparado. Sea como fuera, los problemas relativos a la agencia humana ya son de por sí suficientemente importantes como para justificar la revisión de la concepción acerca de qué es estar preparado y cómo se relaciona con el actuar de manera responsable.

\section{Conclusiones}

Falibilidad y normatividad. Un análisis filosófico de la suerte representa una aportación muy significativa para los debates en torno a la naturaleza de la suerte y su papel en nuestras prácticas evaluativas. El libro goza de dos grandes méritos: Por un lado, presenta una concepción

\footnotetext{
${ }^{4}$ Para una introducción a las explicaciones funcionalistas de este tipo, véanse Millikan 1989 y Wright 1973.
} 
nueva capaz de unificar problemas que tradicionalmente se abordan de manera separada, presentándolos como casos en los que nuestras evaluaciones distinguen entre la obtención del fin previsto y el hecho de estar preparado para alcanzarlo. Por otro lado, ofrece una teoría de la suerte especialmente bien diseñada para dar cuenta del importante papel que le otorgamos a esta idea en las evaluaciones de la agencia en contextos muy distintos.

Si bien es cierto que la noción de estar preparado no es del todo satisfactoria, en especial en lo que atañe a su conexión con actuar responsablemente, aun así se trata de una obra de gran relevancia para todos los lectores hispanohablantes interesados en los problemas filosóficos relacionados con la suerte. Es además un libro claro y accesible, repleto de ejemplos muy ilustrativos que bien puede servir como texto introductorio para estudiantes y lectores poco familiarizados con las cuestiones que aquí se abordan. ${ }^{5}$

Referencias bibliográficas

Barceló Aspeitia, Axel Arturo, 2019, Falibilidad y normatividad. Un análisis filosófico de la suerte, Cátedra, Madrid.

Broncano-Berrocal, Fernando, 2015, "Luck as Risk and the Lack of Control Account of Luck", Metaphilosophy, vol. 46, no. 1, pp. 1-25.

MacFarlane, John, 2014, Assessment Sensitivity. Relative Truth and its Applications, Oxford University Press, Oxford.

Millikan, Ruth Garrett, 1989, "In Defense of Proper Functions", Philosophy of Science, vol. 56, no. 2, pp. 288-302.

Williams, Bernard, 1981, "Moral Luck", en Bernard Williams, Moral Luck. Philosophical Papers 1973-1980, Cambridge University Press, Cambridge.

Wright, Larry, 1973, "Functions", Philosophical Review, vol. 82, no. 2, pp. 139168.

Recibido el 25 de septiembre de 2020; revisado el 23 de diciembre de 2020; aceptado el 23 de diciembre de 2020.

${ }^{5}$ Este trabajo fue posible gracias al Programa de Formación de Personal No Doctor del Departamento de Educación del Gobierno Vasco y se enmarca dentro del proyecto "Autonomía intelectual en contextos de dependencia epistémica" (FFI2017-87395-P) del Ministerio de Economía y Competitividad de España. Quiero agradecer también al profesor Barceló por el diálogo que mantuvimos durante su visita a la UAM y que motivó este trabajo. 